\title{
Isolate-specific effects of ultraviolet radiation on photosynthesis, growth and mycosporine-like amino acids in the microbial mat-forming cyanobacterium Microcoleus chthonoplastes
}

\author{
Bagmi Pattanaik • Michael Y. Roleda • \\ Rhena Schumann • Ulf Karsten
}

Received: 26 September 2007 / Accepted: 31 October 2007 / Published online: 20 November 2007

(c) Springer-Verlag 2007

\begin{abstract}
Microcoleus chthonoplastes constitutes one of the dominant microorganisms in intertidal microbial mat communities. In the laboratory, the effects of repeated daily exposure to ultraviolet radiation (16:8 light:dark cycle) was investigated in unicyanobacterial cultures isolated from three different localities (Baltic Sea $=$ WW6; North Sea $=$ STO and Brittany = BRE). Photosynthesis and growth were measured in time series (12-15 days) while UV-absorbing mycosporine-like amino acids (MAAs) and cellular integrity were determined after 12 and 3 days exposure to three radiation treatments [PAR $(22 \mu \mathrm{mol}$ photon $\left.\mathrm{m}^{-2} \mathrm{~s}^{-1}\right)=\mathrm{P} ; \quad \mathrm{PAR}+\mathrm{UV}-\mathrm{A} \quad\left(8 \mathrm{~W} \mathrm{~m}^{-2}\right)=\mathrm{PA}$; $\left.\mathrm{PAR}+\mathrm{UV}-\mathrm{A}+\mathrm{UV}-\mathrm{B} \quad\left(0.4 \mathrm{~W} \mathrm{~m}^{-2}\right)=\mathrm{PAB}\right]$. Isolate-specific responses to UVR were observed. The proximate response to radiation stress after 1-day treatment showed that isolate WW6 was the most sensitive to UVR. However, repeated exposure to radiation stress indicated that photosynthetic efficiency $\left(F_{\mathrm{v}} / F_{\mathrm{m}}\right)$ of WW6 acclimated to UVR. Conversely, although photosynthesis in STO exhibited
\end{abstract}

B. Pattanaik · R. Schumann · U. Karsten

Institute of Biological Sciences, Applied Ecology,

University of Rostock, Albert-Einstein-Str. 3,

18051 Rostock, Germany

M. Y. Roleda

Institute for Polar Ecology, University of Kiel,

Wischhofstrasse 1-3, Bldg. 12, 24148 Kiel, Germany

Present Address:

B. Pattanaik $(\square) \cdot$ M. Y. Roleda

Department of Marine Ecology, Marine Botany,

Göteborg University, Carl Skottsbergs gata 22b,

40530 Göteborg, Sweden

e-mail: bagmibt@yahoo.co.in lower reduction in $F_{\mathrm{v}} / F_{\mathrm{m}}$ during the first day, the values declined over time. The BRE isolate was the most tolerant to radiation stress with the lowest reduction in $F_{\mathrm{v}} / F_{\mathrm{m}}$ sustained over time. While photosynthetic efficiencies of different isolates were able to acclimate to UVR, growth did not. The discrepancy seems to be due to the higher cell density used for photosynthesis compared to the growth measurement. Apparently, the cell density used for photosynthesis was not high enough to offer self-shading protection because cellular damage was also observed in those filaments under UVR. Most likely, the UVR acclimation of photosynthesis reflects predominantly the performance of the surviving cells within the filaments. Different strategies were observed in MAAs synthesis. Total MAAs content in WW6 was not significantly different between all the radiation treatments. In contrast, the additional fluence of UV-A and UV-B significantly increased MAAs synthesis and accumulation in STO while only UV-B fluence significantly increased MAAs content in BRE. Regardless of the dynamic photosynthetic recovery process and potential UV-protective functions of MAAs, cellular investigation showed that UV-B significantly contributed to an increased cell mortality in single filaments. In their natural mat habitat, $M$. chthonoplastes benefits from closely associated cyanobacteria which are highly UVR-tolerant due to the production of the extracellular UV-sunscreen scytonemin.

Keywords Cyanobacteria - Microbial mats .

$F \mathrm{v} / F \mathrm{~m} \cdot \mathrm{UV}$-absorbing compounds
Abbreviations
Chl $a \quad$ Chlorophyll $a$
MAAs Mycosporine-like amino acids
PAR Photosynthetically active radiation
UVR Ultraviolet radiation 


\section{Introduction}

Microbial mats often develop and form an integral component of intertidal flats and salt marsh across biogeographic regions. The filamentous cyanobacterium Microcoleus chthonoplastes is a cosmopolitan species and the dominant organism in many microbial mat communities growing in the intertidal and hypersaline habitats (Prufert-Bebout and Garcia-Pichel 1994; Stal 1995; Garcia-Pichel et al. 1996). This benthic organism grows by adhering to submerged solid surfaces or attached to interfaces of the subsurface sediment layer in the intertidal zone. Microbial mats are important primary producers in extreme habitats with significant contribution to trophic energy dynamics. Moreover, they also play an important role in the formation, stabilization and biogeochemistry of intertidal sediments (Paterson 1994; Decho 2000).

In their natural habitats, microbial mats are exposed to strong irradiance, high salinity and long-term desiccation (Potts 1994; Bebout and Garcia-Pichel 1995; Karsten 1996). Enhanced solar radiation due to stratospheric ozone depletion is a major stress factor to many photosynthetic organisms in high latitudes (Cockell and Knowland 1999; Day 2001; Häder et al. 2007). High ambient doses of UV radiation (UVR) are, however, characteristic of warm temperate to tropical regions and are strong enough to affect marine organisms in the intertidal zone even under normal stratospheric ozone concentrations (Fleischmann 1989). Although UV-B comprises a negligible portion of sunlight, it is responsible for most of the sun's damaging effects.

UV-B radiation has many detrimental effects on aquatic and terrestrial photosynthetic organisms. These include damaging molecular targets such as nucleic acids and proteins affecting various physiological and biochemical processes which may consequently alter community structure and function when an organism is not able to cope with this stress factor and hence is eliminated in the trophic network (De Nys and Steinberg 2002; Sinha et al. 2003; Pattanaik and Adhikary 2004; Pattanaik et al. 2004; Bancroff et al. 2007). Many benthic cyanobacteria particularly those exposed to high irradiation, however, have developed effective strategies to counteract the damaging effects of UV-B. These include avoidance, i.e. by downward migration into the mat communities (Quesada and Vincent 1997); repair, i.e. D1 protein synthesis to restore PSII function, excision and photoreactivation to repair DNA lesions or gene expression encoding replacement of bleached chlorophylls (Castenholz and Garcia-Pichel 2000); and several other protection strategies (Pattanaik et al. 2007).

Synthesis of antioxidants and detoxifying enzymes can scavenge UV-induced excited states and reactive oxygen species (Vincent and Quesada 1994; Shirkly et al. 2000; He and Häder 2002). Another protective mechanism against enhanced UV-B is the biosynthesis and accumulation of sunscreen compounds like the yellow-brown lipid-soluble scytonemin that occurs predominantly in the extracellular sheaths of cyanobacteria playing an eminent role in preventing UVinduced photodamage (Garcia-Pichel et al. 1992). Caroteniods, which are concentrated mainly in thylakoid membrane, cell membranes, and cell walls of cyanobacteria, also protect cells from lethal effect of photooxidation by singlet oxygen (Edge et al. 1997; Kerfeld 2004). Other important compounds for photoprotection are the mycosporine-like amino acids (MAAs) that have been found in many cyanobacterial species (Garcia-Pichel and Castenholz 1993; Ehling-Schulz et al. 1997). Their role as intracellular passive screening agents has been inferred from UV-induced inhibition of growth and photosynthesis in phototrophic microorganisms lacking or exhibiting low concentrations of MAAs compared to cells with high MAAs contents (Neale et al. 1998).

About 20 different MAAs have been identified, mainly in aquatic organisms from a wide taxonomic range (Cockell and Knowland 1999). Although cyanobacteria also exhibit a broad set of MAAs, in most cases the underlying chemical structures have still to be elucidated (Garcia-Pichel and Castenholz 1993). Specific MAAs compounds have been identified in several isolates and species of Microcoleus from different geographical location, including some taxa lacking these compounds (Karsten and Garcia-Pichel 1996). However, the occurrence of novel MAAs particularly in two strains from the Baltic Sea indicated some degree of either biogeographical or ecotypic diversification (Karsten and Garcia-Pichel 1996). Ultraviolet radiation and osmotic stress have been reported to induce and regulate MAAs synthesis in cyanobacteria (Portwich and GarciaPichel 1999), but M. chthonoplastes exhibited an isolatespecific response (Karsten 2002).

To our knowledge, no physiological studies have been conducted on the performance of $M$. chthonoplastes under UVR stress. Three isolates originally isolated from biogeographically different regions, cultured for many years under identical laboratory conditions were selected to test their tolerance to UVR. We hypothesize that the different strains are able to acclimate to artificial radiation treatments and the UVR response is species-specific rather than isolatespecific. To answer this question, photosynthesis, growth, MAAs synthesis and cellular integrity were comparatively investigated after a long-term repeated exposure to UVR.

\section{Materials and methods}

Organisms and growth condition

The three isolates of Microcoleus chthonoplastes Thuret used in this study were the dominant organism in the 
respective intertidal microbial mat communities at the biogeographically different locations (Table 1). The strains were grown as batch cultures in 300-mL Erlenmeyer flasks in membrane-filtered, sterile Baltic seawater (salinity 12) adjusted to a salinity of 33 with artificial sea salt (Wimex, Wiegand, Krefeld, Germany) and enriched with trace elements to yield Provasoli-enriched seawater (PES, Starr and Zeikus 1987). The vessels were maintained at $22^{\circ} \mathrm{C}$ under $22 \mu \mathrm{mol}$ photons $\mathrm{m}^{-2} \mathrm{~s}^{-1}$ of PAR provided by daylight Osram L18W/19 (Osram, München, Germany) under a 16:8 h light:dark cycle.

\section{Radiation treatment}

An experimental bank was prepared to expose samples under artificial radiation consisting of different spectra emitted by daylight Osram L18W/19 and Q-Panel UVA340 fluorescent tubes (Q-Panel, Cleveland, OH, USA) providing $22 \mu \mathrm{mol}$ photons $\mathrm{m}^{-2} \mathrm{~s}^{-1}\left(=4.73 \mathrm{~W} \mathrm{~m}^{-2}\right)$ PAR, $8 \mathrm{~W} \mathrm{~m}^{-2} \mathrm{UV}-\mathrm{A}$ and $0.4 \mathrm{~W} \mathrm{~m}^{-2} \mathrm{UV}-\mathrm{B}$. Radiation was measured with a Li-Cor LI-190-SB cosine corrected sensor connected to a Li-Cor LI-1000 data logger (Lambda Instruments, Lincoln, NE, USA) for PAR and PMA broadband radiometer for UV (Solar Light Co., Philadelphia, PA, USA). To achieve different radiation treatments consisting of PAR alone (P), PAR + UV-A (PA) and PAR + UV$\mathrm{A}+\mathrm{UV}-\mathrm{B}$ (PAB), different cut-off filters were used. Petri dishes were covered with a 395-nm cut-off filter foil (Ultraphan URUV, Digefra, München, Germany) to eliminate UV-A and UV-B radiations, a 320-nm cut-off filter foil (Folex PR, Folex, Dreieich, Germany) to eliminate UV-B, and a 295-nm cut-off filter (Ultraphan UBT, Digefra) to allow transmission of wavelengths $>295 \mathrm{~nm}$. The available cut-off filters slightly differed from the UVR definition of CIE (Commission Internationale De l'Eclairage, UV$\mathrm{A}=315-400 \mathrm{~nm}, \mathrm{UV}-\mathrm{B}=280-315 \mathrm{~nm})$.

\section{Photosynthesis}

Photosynthetic efficiency was measured as in vivo Chl $a$ fluorescence using a portable pulse amplitude modulated fluorometer (PAM2000, Walz, Effeltrich, Germany). The optimum quantum yield $\left(F_{\mathrm{v}} / F_{\mathrm{m}}\right)$ of photochemistry was determined in cyanobacteria suspension exposed to different radiation treatments. A thick suspension of $M$. chthonoplastes with initial $F_{0}=1,000 \mathrm{mV}$ was prepared for experimental treatments. Optimum quantum yield of photosynthesis was measured in control $(n=9)$ and in samples exposed under $\mathrm{P}, \mathrm{PA}$ and $\mathrm{PAB}(n=3)$. Experimental units were repeatedly exposed to $16 \mathrm{~h}$ light and $8 \mathrm{~h}$ dark photoperiod for 12 days. $F_{\mathrm{v}} / F_{\mathrm{m}}$ was measured directly after the $16 \mathrm{~h}$ radiation exposure at day 1, 3, 6, 9, and 12. Samples were initially dark incubated for 10-15 min before $F_{\mathrm{v}} / F_{\mathrm{m}}$ measurements. $\mathrm{F}_{0}$ was determined by a pulsed measuring beam (ca. 0.3$0.4 \mu \mathrm{mol}$ photons $\mathrm{m}^{-2} \mathrm{~s}^{-1}, 650 \mathrm{~nm}$ ), followed by short pulses of saturating white light $(0.6-0.8 \mathrm{~s}, 2,000-$ $5,000 \mu \mathrm{mol}$ photons $\mathrm{m}^{-2} \mathrm{~s}^{-1}$ ) for recording $F_{\mathrm{m}}$ (distance light conductor: $1 \mathrm{~mm}$, angle: $90^{\circ}$ ).

\section{Growth}

For each isolate, nine experimental units were prepared. From the growth cultures, $1 \mathrm{~mL}$ suspensions were transferred to each 30-mL transparent polyacryl Petri dishes (Kleinfeld, Hannover, Germany) and filled with $19 \mathrm{~mL}$ of PES medium.

Initial density of cyanobacteria in all experimental units was standardized by measuring initial Chl $a$ fluorescence $\left(F_{0}\right)$ between 200-300 mV. Samples were then repeatedly exposed under $16 \mathrm{~h}$ of $\mathrm{P}, \mathrm{PA}$ and $\mathrm{PAB}$ and $8 \mathrm{~h}$ dark period for 12-15 days. Petri dishes were maintained inside a water bath to keep a constant temperature of $22^{\circ} \mathrm{C}$. Daily growth measurements $(n=3)$ were performed as the increase in Chl $a$ fluorescence using an in vivo growth fluorometer for phototrophic microorganisms as previously described by Karsten et al. (1996). The growth rate $(\mu)$ was derived from iterative optimization of the exponential growth curves using the equation:

$F_{t}=F_{0} \mathrm{e}^{\mu t}\left(F_{0}\right.$ : initial fluorescence; $F_{t}$ : fluorescence after $t$ days)

\section{Mycosporine-like amino acids (MAAs)}

MAAs concentrations were determined in samples exposed to the same radiation $(\mathrm{P}, \mathrm{PA}, \mathrm{PAB})$ and exposure treatments as for photosynthesis and growth using $40 \mathrm{~mL}$ of $M$. chthonoplastes suspension. After 12 days, the suspensions were centrifuged at $6,900 \mathrm{~g}$ for $5 \mathrm{~min}$ to collect the filaments. Pellets were rinsed twice in ice-cold iso-osmotic $\mathrm{Ca}\left(\mathrm{NO}_{3}\right)_{2}$ solutions to remove the extracellular dominant ions of the

Table 1 Microcoleus chthonoplastes cultures in 33 salinity PES medium maintained at the University of Rostock

\begin{tabular}{lll}
\hline Isolate culture no. & Collection locality & Collection date \\
\hline WW6 & Großer Werder, Zingst, Germany (Intertidal windflat, Baltic Sea) & 15 June 2002 \\
STO & Westhever, St. Peter Ording, Germany (Intertidal mudflat, North Sea) & 22 March 1995 \\
BRE & Sables D’Or, Brittany, France (Intertidal salt marsh, Atlantic coast) & 10 September 2001 \\
\hline
\end{tabular}


salt water medium in the filaments as described by Karsten et al. (1991). Afterwards samples were freeze-dried (Lyovac GT2, Thermo Quest Scientific Equipment Group, Egelsbach, Germany). Dried samples of about $5 \mathrm{mg}$ dry weight were extracted for $1.5-2 \mathrm{~h}$ in screw-capped centrifuge vials filled with $1 \mathrm{~mL} 25 \%$ aqueous methanol (v/v) and incubated in a water bath at $45^{\circ} \mathrm{C}$. After centrifugation at $6,900 \mathrm{~g}$ for $5 \mathrm{~min}, 900 \mu \mathrm{L}$ of the supernatants were evaporated to dryness under vacuum (Speed Vac Concentrator SPD $111 \mathrm{~V}$, Thermo Quest Scientific Equipment Group). Dried extracts were redissolved in $300 \mu \mathrm{L} 100 \%$ methanol and vortexed for $30 \mathrm{~s}$. After passing through $0.2-\mu \mathrm{m}$ membrane filter, samples were analyzed with an Agilent HPLC (Waldbronn, Germany) system according to the method of Carreto et al. (2005). The MAAs were separated on a stainless steel Altima (Alltech) C18 $(5 \mu 150 \times 4.6 \mathrm{~mm})$ and CapCell Pak UG (Shiseido) C18 $(5 \mu 250 \times 4.6 \mathrm{~mm})$ protected by Phenomenex guard column C18 (Phenomenex, Aschaffenburg, Germany). The mobile phase with Eluent A: $0.2 \%$ trifluoroacetic acid adjusted with ammonium hydroxide to $\mathrm{pH} 3.15$ and Eluent B: $0.2 \%$ trifluoroacetic acid adjusted with ammonium hydroxide to $\mathrm{pH} 2.2$ : methanol: acetonitrile $=80: 10: 10$ (by vol.), run isocratically at a flow rate of $1 \mathrm{~mL} \mathrm{~min}^{-1}$. The MAAs were detected online with a photodiode array detector at $330 \mathrm{~nm}$, and absorption spectra (290-400 nm) were recorded each second directly on the HPLC-separated peaks. Identification and quantification of MAAs were done by spectra, retention time, and cochromatography with some available standards (Karsten et al. 1998a).

\section{Cellular structure}

Micrographs of the isolates studied were taken before and after 3 days of $16 \mathrm{~h}$ daily UVR exposure. Filaments were examined with a fluorescent light microscope (Olympus IX70, 20× objective, excitation wavelengths $510-550 \mathrm{~nm}$, emission peak >590 nm using a dichroic mirror at $570 \mathrm{~nm}$ ) equipped with a green filter (WG) to observe autofluorescence of PSII (Chl $a$ and accessory pigments). Photographs were taken using a digital camera (Olympus ColorView 12, U-CMAD3, Japan) coupled to a PC and processed using AnalySIS $^{\mathrm{TM}}$ Pro software (3.02 Soft-Imaging Systems). Exposure times were recorded.

\section{Statistics}

Data were tested for homogeneity (Levene Statistics) of variance. Heteroskedastic data were square root transformed. Time series measurements on photosynthesis were subjected to repeat measures analysis of variance (RMANOVA, $P<0.05)$ to determine the effects of radiation treatments separately among different strains. MAAs synthesis and growth rates under varying irradiance were tested using analysis of variance (ANOVA, $P<0.05$ ). All analyses were followed by Duncan's multiple range test (DMRT, $P=0.05)$. Statistical analyses were made using SPSS program (SPSS, Chicago, IL, USA).

\section{Results}

The optimum quantum yield of PSII $\left(F_{\mathrm{v}} / F_{\mathrm{m}}\right)$ of the control (before exposure treatment) already showed significant difference in the photosynthetic capacity between the three isolates (ANOVA, $P=0.001$; DMRT, $P=0.05$ ). Photosynthetic efficiency was highest in the isolate BRE $(0.506 \pm 0.03)$, followed by STO $(0.415 \pm 0.01)$ and lowest in WW6 (0.342 \pm 0.03$)$.

During treatment, repeated exposure to $\mathrm{P}$ had no significant negative effect on the photosynthetic efficiencies of the three isolates. Radiation supplemented with UVR, however, reduced the photosynthetic efficiencies of all isolates (Fig. 1). After 1-day exposure to UVR, reduction in $F_{\mathrm{v}} / F_{\mathrm{m}}$ relative to $\mathrm{P}$ was highest in WW6 with 37 and $53 \%$ decrease in PA and PAB-treated samples, respectively. The relative decrease in $F_{\mathrm{v}} / F_{\mathrm{m}}$ was lower in STO with 35 and $41 \%$ under $\mathrm{PA}$ and $\mathrm{PAB}$, respectively. Minimal and no additional effect of UV-B was observed in the reduction of $F_{\mathrm{v}} / F_{\mathrm{m}}(16-17 \%)$ in UVR-treated BRE isolates (Fig. 1).

Repeated exposure to UVR showed different long-term responses. Curve fits using non-linear regression analysis indicated increasing photosynthetic efficiency in PABtreated WW6 over time. Conversely, the $F_{\mathrm{v}} / F_{\mathrm{m}}$ in PABtreated STO decreased progressively from the 6 th to the 12th day. The photosynthetic performance of UVR-treated BRE remained relatively unchanged over time. Repeated measure analysis of variance (RMANOVA, $P=0.001$ ) showed significant difference between isolates and irradiance, as well as an interactive effect between the two variables (Table 2).

Growth in terms of increase in Chl $a$ fluorescence was detected and calculated in P-treated samples but not in PAand PAB-treated samples of all isolates (Fig. 2). Background $\mathrm{F}_{0}$ in UVR-treated samples was detectable and comparable to the initial values in STO and BRE, which eventually decreased compared to the initial background fluorescence (Fig. 2b, c). In WW6, a minimal growth was detected until the 9th day (Fig. 2a). Growth rate in P-treated samples was not significantly different between the isolates (ANOVA, $P=0.124$ ). Relatively higher growth rates were, however, observed in STO $\left(0.141 \pm 0.02 \mu\right.$ day $\left.^{-1}\right)$ and $\operatorname{BRE}\left(0.131 \pm 0.02 \mu \mathrm{day}^{-1}\right)$ isolates and lowest in WW6 $\left(0.112 \pm 0.01 \mu \mathrm{day}^{-1}\right)$.

Three different UV-absorbing compounds were detected in $M$. chthonoplastes (Fig. 3). The respective absorption 

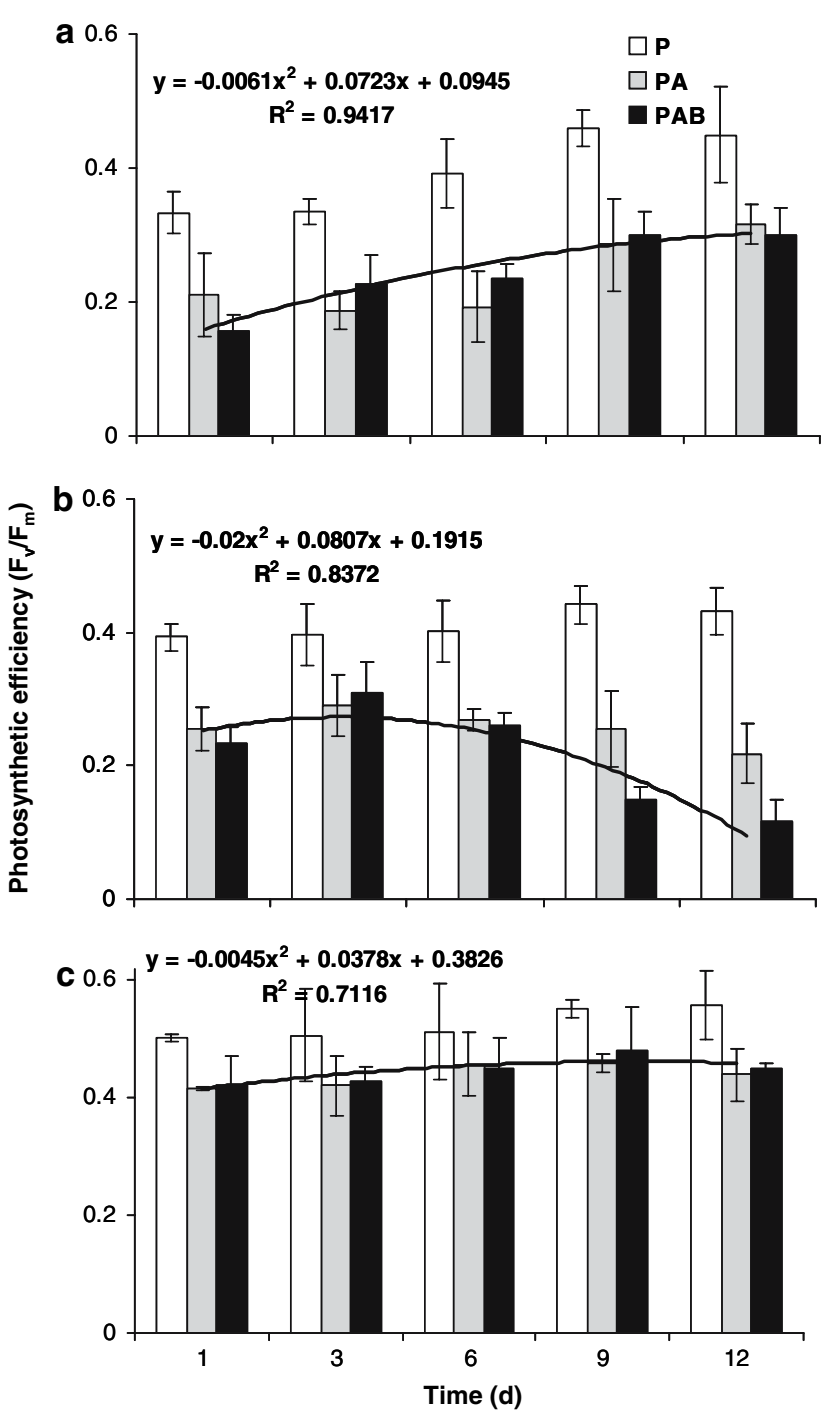

Fig. 1 Time series measurements of the optimum quantum yields (mean $F_{\mathrm{v}} / F_{\mathrm{m}} \pm \mathrm{SD}, n=3$ ) of Microcoleus chthonoplastes isolates (a) WW6, (b) STO and (c) BRE after repeated daily $16 \mathrm{~h}$ exposure to photosynthetically active radiation $(\mathrm{PAR}=\mathrm{P}), \mathrm{PAR}+\mathrm{UV}-\mathrm{A}(\mathrm{PA})$ and $\mathrm{PAR}+\mathrm{UV}-\mathrm{A}+\mathrm{UV}-\mathrm{B} \quad(\mathrm{PAB})$ at different days. PAR $=22 \mu \mathrm{mol}$ photons $\mathrm{m}^{-2} \mathrm{~s}^{-1}$, UV-A $=8 \mathrm{~W} \mathrm{~m}^{-2}$ and UV-B $=0.4 \mathrm{~W} \mathrm{~m}^{-2}$. Solid lines are curve fits using non-linear regression analysis to determine the photosynthetic performance in PAB-treated samples over time. Analysis of variance (ANOVA) is presented in Table 2

profiles were similar in all the three isolates investigated. Two peaks with absorption maxima of $331 \mathrm{~nm}$ were detected at 8.2 and 9.3 min. Another peak was detected at 13.3 min with an absorption maximum of $345 \mathrm{~nm}$ (Fig. 3). None of the available standard MAAs confirmed identity, and hence all MAAs in M. chthonoplastes have still to be chemically elucidated. After 12 days exposure to different radiation treatments, no significant accumulation in UV-absorbing compounds was observed in WW6. In contrast, a significant increase in MAAs content was observed in PA- and PAB-exposed samples of STO. In BRE, only
Table 2 Analysis of variance (ANOVA) and significance values for the main effects and interactions of radiation treatment (spectral irradiance compose of $\mathrm{P}, \mathrm{PA}$, and $\mathrm{PAB}$ ) and $M$. chthonoplastes isolates (WW6, STO, and BRE) on photosynthetic efficiency (repeated measures, RMANOVA) and MAAs (* significant)

\begin{tabular}{lllrr}
\hline Dependent variable & $\begin{array}{l}\text { Independent } \\
\text { variable }\end{array}$ & $d f$ & \multicolumn{2}{l}{$P$} \\
\hline$F_{\mathrm{v}} / F_{\mathrm{m}}$ & Isolate (A) & 2 & 135.027 & $<0.001^{*}$ \\
& Irradiance (B) & 2 & 82.087 & $<0.001^{*}$ \\
& A $\times$ B & 4 & 4.269 & $0.013^{*}$ \\
MAAs (square root) & Isolate (A) & 2 & 7.939 & $0.003^{*}$ \\
& Irradiance (B) & 2 & 19.879 & $<0.001^{*}$ \\
& A $\times$ B & 4 & 5.810 & $0.003^{*}$ \\
\hline
\end{tabular}

$d f(=n-1)$, degree of freedom; $F$, ratio of the model mean square to the error mean square which refers to the data distribution; $P$-value, level of significance of the statistical test

PAB-exposed cells exhibited significant increase in MAAs values (Fig. 4). Multiple analysis of variance (MANOVA, $P<0.01)$ indicated significant effects of isolate and irradiance, as well as interactive effects of isolate and irradiance on MAAs synthesis (Table 2).

The excitation at circa $450 \mathrm{~nm}$ emitted only a weak red autofluorencense of PSII, faintly visible in photograph due to the so-called cyanobacterial blue excitation gap. In lieu of the blue filter, a green filter was chosen because it can excite the minor chlorophyll absorption peak at $580 \mathrm{~nm}$. The green excitation is absorbed primarily by phycoerythrin but this accessory pigment is not highly concentrated in $M$. chthonoplastes, while phycocyanin as the dominating phycobiliprotein is excitable at $>600 \mathrm{~nm}$. The excitation band of phycocyanin is, however, wide and reaches into the excitation wavelength $(<590 \mathrm{~nm})$ used. Thus, the autofluorescence micrograph represents a combined signal of Chl $a$ and phycobilin fluorescence. M. chthonoplastes grown under $\mathrm{P}$ showed densely pigmented filaments, which strongly emitted a red fluorescence (Fig. 5a, b). The red autofluoresence of $\mathrm{Chl} a$ and phycobilins was slightly reduced under PA treatment (Fig. 5c). A strong degradation of primary and accessory pigments was observed under PAB treatment where only a tiny fragment of the filament remained fluorescent and this sample had to be exposed ca. 20 times longer than the others (Fig. 5d).

\section{Discussion}

Physiological and biochemical responses in Microcoleus chthonoplastes under UVR stress were observed to be isolate-specific in samples originally collected from biogeographically different habitats, but cultured under the same laboratory conditions for at least 4 years. Under white light 

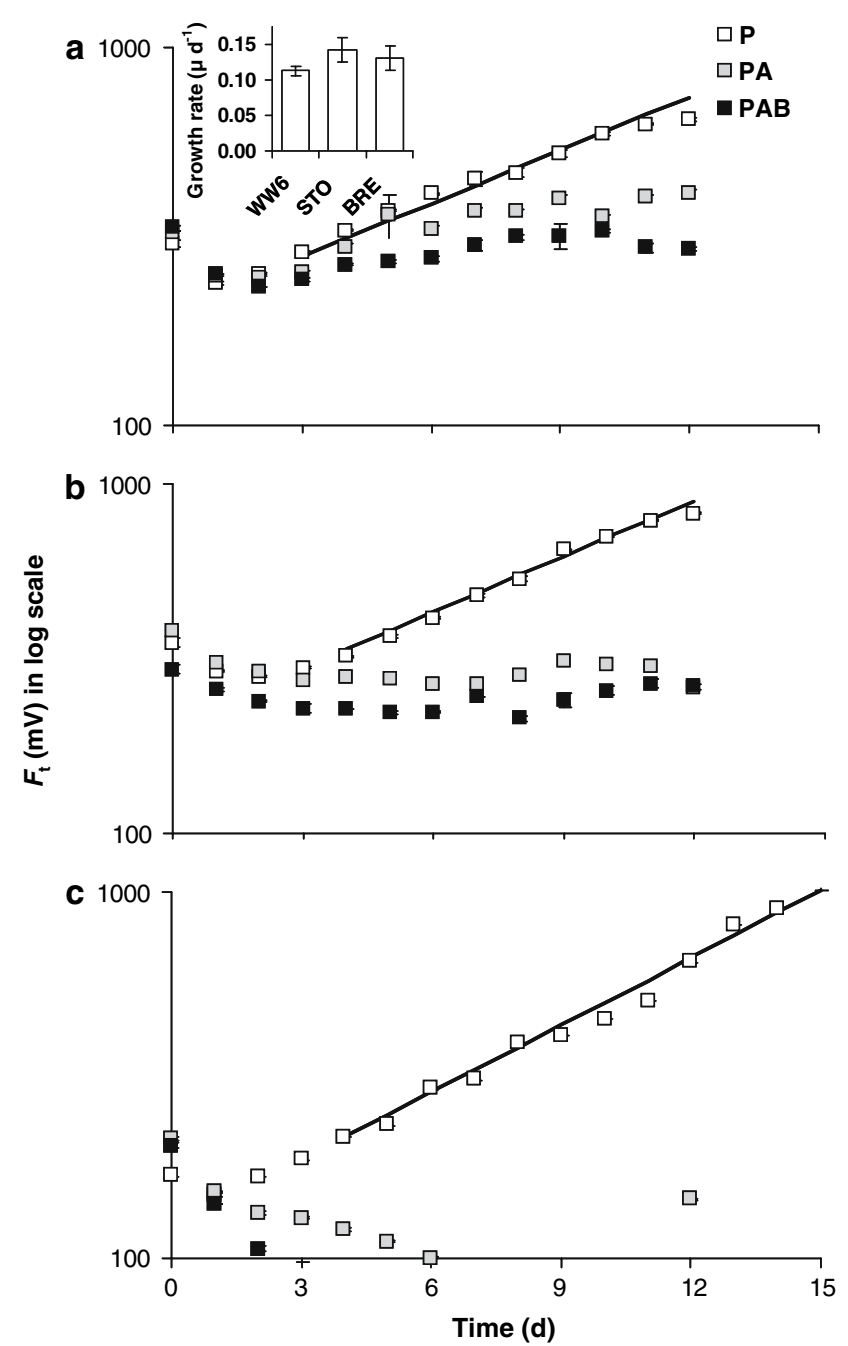

Fig. 2 Growth measurements based on increases in chlorophyll $a$ fluorescence $\left(F_{0}\right)$ of Microcoleus chthonoplastes isolates (a) WW6, (b) STO and (c) BRE after repeated daily $16 \mathrm{~h}$ exposure to photosynthetically active radiation $(\mathrm{PAR}=\mathrm{P}), \mathrm{PAR}+\mathrm{UV}-\mathrm{A}(\mathrm{PA})$ and $\mathrm{PAR}+\mathrm{UV}-$ $A+U V-B(P A B)$. Daily measurements for $P$ treatment (of a representative replicate) were fitted using the exponential growth curve equation $F_{t}=F_{0} \mathrm{e}^{\mu t}$. Inset gives the corresponding growth rate of P-treated samples $\left(\mu\right.$ day $\left.^{-1}, n=3\right)$. ANOVA showed no significant difference between isolates $(P=0.124)$

(PAR), photosynthetic performance was positively correlated to their growth potential although in an isolate-specific manner. UV-B led to Chl $a$ and phycobilin bleaching, thereby contributing to significant cell death of many filaments. Consequently growth was inhibited under PAR + UVR. However, photosynthesis in surviving cells of two isolates recovered to acclimate to UVR but no relationship was observed between acclimation potential and MAA synthesis.

Most studies on the impact of UVR on the photosynthetic performance of algae refer to the mechanism of photoinhibition and recovery after only one-time exposure to UVR and subsequent recovery under low PAR. This approach is important to understand the principal physiological response

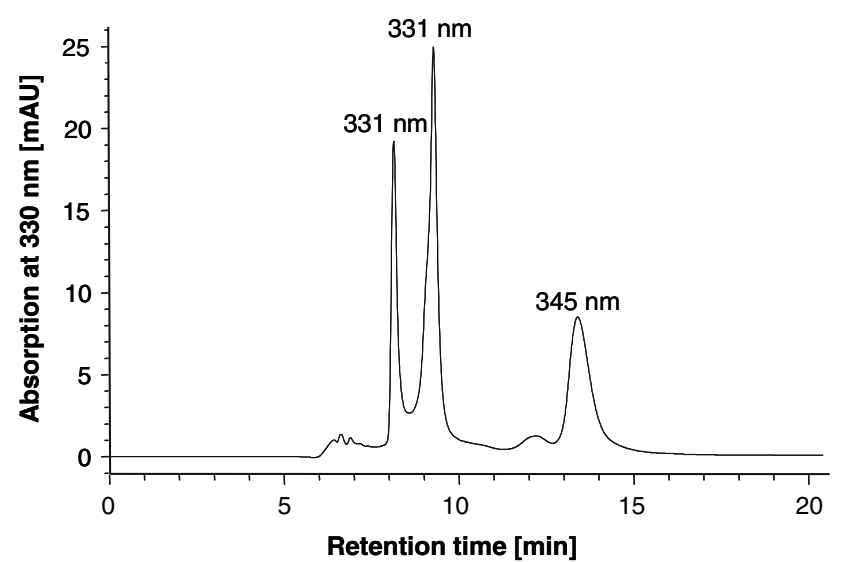

Fig. 3 Representative HPLC chromatogram of Microcoleus chthonoplastes showing three unknown mycosporine-like amino acids. The absorption maxima of the respective peaks are indicated

of organisms to stress factors but imposes strict limits in making ecological implications. Therefore, more studies on photosynthetic performance of phototrophs under long term repeated exposure to UVR are needed. In juvenile stages of macroalgae, young sporophytes of subtidal Laminaria species were only able to partially acclimate to UVR after 28 days of repeated daily exposure to the whole radiation spectrum (Roleda et al. 2004a) while young gametophytes of eulittoral Gigartinales were able to fully acclimate to UVR already after 3 days until the end of the 10-day exposure treatment (Roleda et al. 2004b). In aeroterrestrial biofilm algae, three out of four green algal species tested were able to fully acclimate to ultraviolet radiation in terms of photosynthetic performance and growth after 12 days repeated exposure to artificial radiation in the laboratory (Karsten et al. 2007). In a marine planktonic cyanobacterium Oscillatoria sp., pre-culture of cells with UV-A led to a higher tolerance of cells against UV-A-induced inhibition of photosynthesis (Wachi et al. 1995). While Nostoc sphaeroides is slightly photoinhibited under ambient solar radiation and capable of fast recovery which is typical for dynamic photoinhibition (Helbling et al. 2006), Arthrospira platensis is much more sensitive to UVR but photoinhibition decreased within 1 week of repeated exposure to solar radiation exemplifying partial acclimation of photosynthesis. In $M$. chthonoplastes photosynthetic performance was observed to be isolate-specific where acclimation and deterioration in $F_{\mathrm{v}} / F_{\mathrm{m}}$ was observed in WW6 and STO, respectively. The minimal reduction of $F_{\mathrm{v}} / F_{\mathrm{m}}$ under UVR in BRE was persistent over time maintaining a relatively efficient photosynthetic performance under this waveband.

Since photoinhibition and recovery of photosynthesis as well as D1 protein turnover is a dynamic process, growth as an integrative parameter of all physiological processes, represents a more holistic measure to account for the impact of stress. Growth can be measured in terms of cell number, 


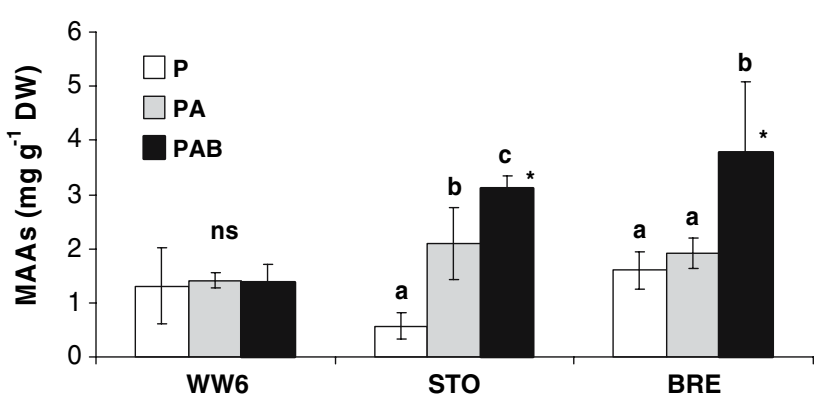

Fig. 4 Total intracellular mycosporine-like amino acid contents (mean MAAs $\pm \mathrm{SD}, n=3$ ) in (a) WW6, (b) STO and (c) BRE isolates of Microcoleus chthonoplastes after 12 days exposure under 16:8 h light:dark cycle of photosynthetically active radiation $(\mathrm{PAR}=\mathrm{P})$, $\mathrm{PAR}+\mathrm{UV}-\mathrm{A}(\mathrm{PA})$ and PAR + UV-A + UV-B (PAB). PAR $=22 \mu \mathrm{mol}$ photons $\mathrm{m}^{-2} \mathrm{~s}^{-1}$, UV-A $=8 \mathrm{~W} \mathrm{~m}^{-2}$ and $\mathrm{UV}-\mathrm{B}=0.4 \mathrm{~W} \mathrm{~m}^{-2}$. Oneway ANOVA showed significant $(*, P<0.05)$ and non-significant effects (ns, $P>0.05$ ) of irradiance in each isolate

biomass, total carbon content and Chl $a$ increase. In this study we determined the increase of in vivo fluorescence of Chl $a$ (Karsten et al. 1996).

Species-specific growth in response to stress factors has been reported in several studies. In the UV-A resistant Oscillatoria sp., growth was observed at UV-A radiation of up to $8 \mathrm{~W} \mathrm{~m}^{-2}$ (Wachi et al. 1995) similar to the UV-A treatment used in the present study. In the aeroterrestrial green alga Myrmecia incisa, growth rate was significantly reduced although this species was able to photosynthetically acclimate to UVR. In contrast, growth rates of Stichococcus sp. and Chlorella luteoviridis were similar between PAR and PAR + UVR treatments. The PAR + UV-A treatment significantly reduced growth rate in Desmodesmus subspicatus, while the addition of UV-B was accompanied by a complete inhibition of growth (Karsten et al. 2007). In the present study, no substantial growth was observed in all isolates of $M$. chthonoplastes exposed to PA and PAB, although the irradiances were similar to those used by Karsten et al. (2007). Under PA treatment, where slight bleaching of filaments was observed, pigments (Chl $a$ and phycobilins) could have been slightly degraded resulting in a lower autofluorescence per cell. Under this condition, cell survival would entail higher metabolic cost for maintenance and therefore no net growth was observed after longer exposure time while only a minimal growth was measured in WW6 within the first 6 days of exposure. However, under much higher UVR $\left(53.1 \mathrm{~W} \mathrm{~m}^{-2} \mathrm{UV}-\mathrm{A}\right.$; $\left.1.3 \mathrm{~W} \mathrm{~m}^{-2} \mathrm{UV}-\mathrm{B}\right)$, A. platensis exhibited detectable but reduced growth rates (Helbling et al. 2006). Acclimation and maintenance of efficient photosynthetic performance under UVR in WW6 and BRE were most probably measured from surviving cells. Microscopic examination of the cyanobacterial filaments, however, pointed to high incidence of cell mortality in PAB treatment, which supports the measured growth inhibition.

While photosynthetic efficiencies of all isolates seem to be able to acclimate to UVR, growth did not. This discrepancy can be, at least partially, related to the methods used, which are both based on the fluorescence of Chl $a$. If this pigment decreases under UVR (degradation or bleaching), this would potentially influence the quality of the data. Consequently, continuously declining Chl $a$ concentrations in growing cells under UVR exposure will lead to an underestimation of the growth rate, and at the same time to an overestimation of the dark yield of photosynthesis. The extent of this potential problem should be carefully addressed in future UV-studies.

The discrepancy between photosynthetic performance and growth may also be attributed to the different cell densities used for the photosynthesis and growth measurements. A minimal initial fluorescence $\left(F_{0}=200 \mathrm{mV}\right)$ is needed to continuously detect changes in $F_{t}$ over time as a measure for growth without overloading the dynamic range
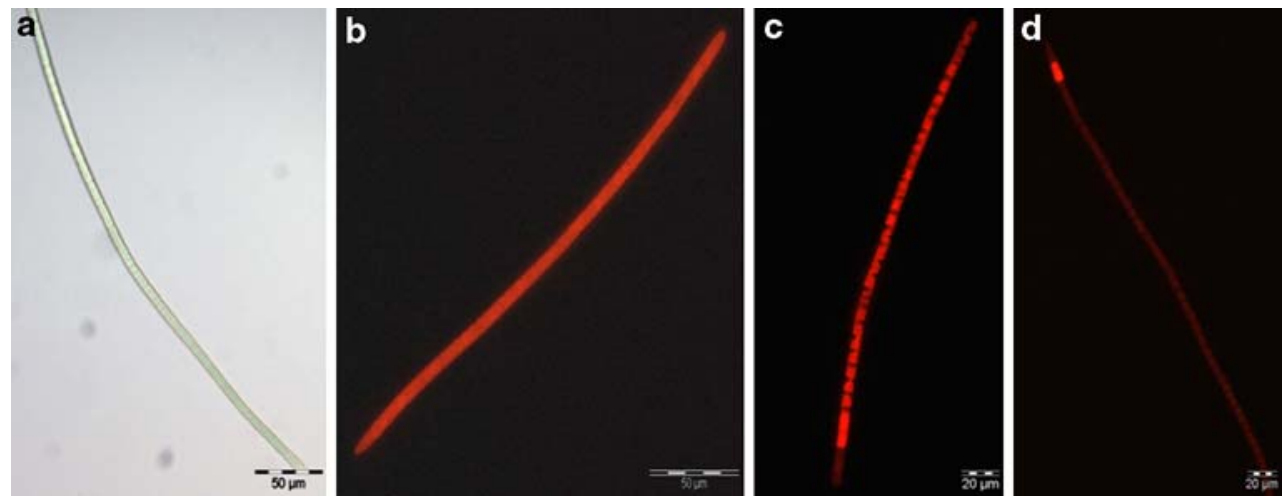

Fig. 5 Microcoleus chthonoplastes filaments. a Transmitted light image. b, c, $\mathbf{d}$ Chlorophyll $a$ and accessory pigments autofluorescence in red after 3 days repeated exposure under 16:8 h light:dark cycle in (a, b) photosynthetically active radiation $(\mathrm{PAR}=\mathrm{P}), \mathbf{c} \mathrm{PAR}+\mathrm{UV}-\mathrm{A}(\mathrm{PA})$ and d PAR + UV-A + UV-B (PAB). Images represent STO isolate. Scale bars $=50(\mathbf{a}, \mathbf{b})$ and $20 \mu \mathrm{m}(\mathbf{c}, \mathbf{d})$. Exposure times are $64(\mathbf{b}), 57$ (c) and $990 \mathrm{~ms}(\mathbf{d})$ 
of the growth fluorometer used. On the other hand, the PAM 2000 fluorometer requires a much higher initial fluorescence $\left(F_{0}=1,000 \mathrm{mV}\right)$ with cyanobacterial cell suspension to measure $F_{\mathrm{v}} / F_{\mathrm{m}}$ accurately. With the denser suspension used for photosynthetic measurements, it might be likely that self shading could have reduced the UVR stress of individual cells to sustain a relatively high photosynthetic performance. The microscopic observations were however carried out on dense suspensions similar to those used for photosynthesis measurements. The UVR acclimation observed in different Microcoleus isolates can therefore be attributed to the performance of the surviving cells within the filaments. Degraded cells retain their cell walls, which can offer some protective function to the surviving cells by attenuating UVR. This has been well documented in the field for the green macroalga Ulva aff. rotundata Bliding from Southern Spain. At the natural site, the top layer of these mat-like canopies is generally completely bleached, but acts as a selective UV-B filter, and thus prevents subcanopy thalli from exposure to harmful radiation (Bischof et al. 2002). Cells and tissue of brown algae that contain UV-absorbing compounds have the potential to protect any underlying living cells from the harmful effect of high levels of UVR. Among different kelp species, release of a cloud of meiospores (with phlorotannin-containing physodes) could buffer each other effectively acting as a UV-biofilter (Roleda et al. 2006). The superficial meristoderm cells of a fucoid brown alga Hormosira banksii damaged by excess solar radiation was also observed to protect inner cells, remaining healthy, apparently shielded by the phlorotannin-rich dead tissue (Schoenwaelder 2002).

Impact of UVR on the morphology of A. platensis indicated filament breakage or formation of tight helical structures as some kind of photoprotective mechanism (Wu et al. 2005; Helbling et al. 2006). Conversely, no significant changes were observed in the morphology of $N$. sphaeroides under different radiation treatments (Helbling et al. 2006). The terrestrial cyanobacteria Nostoc microscopicum and Tolypothrix arenophila possessing scytonemin as UVA absorbing pigment in the extracellular sheath layer were able to tolerate $48 \mathrm{~h}$ continuous UV-B radiation. After $60 \mathrm{~h}$ exposure, the cells were observed to be extruded from the trichome (Pattanaik and Adhikary 2004). In contrast, Aulosira fertilissima lacking scytonemin bleached after $6 \mathrm{~h}$ UV-B radiation (Pattanaik and Adhikary 2004). In the present study, the images taken before and after exposure to different radiation conditions indicated a differential decrease in the auto-fluorescence of pigments in PA- and PAB-treated filaments relative to PAR exposure indicating the degradation of Chl $a$ and phycobilins, as well as the increase in cell mortality under UVR.

Production of UV-absorbing compounds such as mycosporine-like amino acids (MAAs) have been related to photoprotection, which confer tolerance to high PAR and UVR. Three novel MAAs with absorbance maxima at 344, 346 and $332 \mathrm{~nm}$ in different isolates of $M$. chthonoplastes have been previously reported (Karsten and Garcia-Pichel 1996; Karsten 2002). In this study, we detected maximum absorbances only at 345 and $331 \mathrm{~nm}$, however the underlying chemical structures have still to be elucidated.

Although the role that MAAs play as sunscreen compounds to protect against UVR-induced damage is well established, the relationship between MAAs synthesis and physiological performance in $M$. chthonoplastes is isolatespecific rather than a ubiquitous response. The lower sensitivity of PSII in BRE after repeated exposure to UVR is related to strong accumulation of MAAs in PAB-treated cells. Similar protective function of MAAs against inhibition of photosynthesis was reported in the dinoflagellate Gymnodinium sanguineum and cyanobacterium Plectonema boryanum (Neale et al. 1998; Ivanov et al. 2000). On the other hand, photosynthesis of WW6 was able to partially acclimate to UVR but without significant difference in MAAs contents between PAR and PAR + UVR treated cells. The same phenomenon was observed in A. platensis which required a long-term acclimation process to cope with high UVR levels, which seem not to be related to the accumulation of UV-absorbing compounds rather than to adaptive morphological changes (Helbling et al. 2006). Conversely, photosynthesis of STO under UVR slightly deteriorated over time but a significant difference in MAAs content was observed between treatments. Synthesis of MAAs as UV protectants is energetically expensive. Organisms of 1 to $<10 \mu \mathrm{m}$ cell size $(M$. chthonoplastes cells diameter $=2.6-6.9 \mu \mathrm{m}$; Karsten and Garcia-Pichel 1996) using UV sunscreens as photoprotective mechanisms can gain considerable physiological benefits but at the expense of high energetic investment and sometimes with restricted efficiency (Garcia-Pichel 1994). A significant positive correlation between growth rate and MAAs accumulation among different species of aeroterrestrial biofilm algae was reported by Karsten et al. (2007). On the other hand, strain-specific physiological responses (pigment, $F$ V/ $F \mathrm{~m}$ and growth) in UVR- exposed Nodularia spumigena were not related to MAAs accumulation (Wulff et al. 2007).

In their natural habitat, microbial mats typically consist of associations of different cyanobacterial taxa. In these systems Lyngbya cf. aestuarii has been reported to form thin compact layers on top of $M$. chthonoplastes. Exposure to high solar radiation stimulated in $L$. cf. aestuarii synthesis and accumulation of scytonemin which effectively protected M. chthonoplastes like an umbrella underneath from UVR allowing optimum growth in summer (Karsten et al. 1998b). In addition, many motile cyanobacteria have been reported to migrate downward into the mat particularly at noon as radiation avoidance strategy (Bebout and Garcia-Pichel 
1995; Castenholz 1997; Kruschell and Castenholz 1998; Nadeau et al. 1999).

In summary, $M$. chthonoplastes isolated from different localities and grown under the same laboratory conditions for years were able to maintain ecotypic characteristics that might be genetically fixed as shown in their variable physiological response to UVR. Morphologically, the different isolates are classified as one species. Molecular taxonomic approaches such as $16 \mathrm{~S}$ and ITS rDNA sequencing will determine the relatedness of the different isolates studied to explain the observed isolate-specific responses to UVR. In general, cellular integrity and growth of different $M$. chthonoplastes isolates were sensitive to the experimental UVRtreatments in the laboratory. However, in nature this species survives the high-radiation environment by living in close association with UVR-tolerant and scytonemin producing cyanobacteria and because of the ability to migrate to more shaded locations.

Acknowledgments We thank S. Lembcke, S. Görs and L. Gustavs for excellent technical support with HPLC and laboratory assistance. BP thanks Boehringer Ingelheim Fonds (BIF), Germany for the research scholarship grant and the Swedish Institute for the current fellowship. UK gratefully acknowledges financial support by the Deutsche Forschungsgemeinschaft (DFG).

\section{References}

Bancroff BA, Baker NJ, Blaustein AR (2007) Effects of UVB radiation of marine and freshwater organisms: a synthesis through metaanalysis. Ecol Lett 10:332-345

Bebout BM, Garcia-Pichel F (1995) UV B-induced vertical migrations of cyanobacteria in a microbial mat. Appl Environ Microbiol 61:4215-4222

Bischof K, Peralta G, Kraebs G, van de Poll WH, Perez-Llorens JL, Breeman AM (2002) Effects of solar UV-B radiation on canopy structure of Ulva communities from southern Spain. J Exp Bot 53:2411-2421

Carreto JI, Carignan MO, Montoya NG (2005) A high-resolution reverse-phase liquid chromatography method for the analysis of mycosporine-like amino acids (MAAs) in marine organisms. Mar Biol 146:237-252

Castenholz RW (1997) Multiple strategies for UV tolerance in cyanobacteria. Spectrum 10:10-16

Castenholz RW, Garcia-Pichel F (2000) Cyanobacterial responses to UV-radiation. In: Whitton BA, Potts M (eds) Ecology of cyanobacteria. Their diversity in time and space. Kluwer, Dordrecht, pp 591-611

Cockell CS, Knowland J (1999) Ultraviolet radiation screening compounds. Biol Rev 74:311-345

Day TA (2001) Ultraviolet radiation and plant ecosystems. In: Cockell CS, Blaustein AR (eds) Ecosystems, evolution, and ultraviolet radiation. Springer, Heidelberg, pp 80-117

De Nys R, Steinberg PD (2002) Linking marine biology and biotechnology. Curr Opin Biotechnol 13:24-248

Decho AW (2000) Microbial biofilms in intertidal systems: an overview. Cont Shelf Res 20:1257-1273

Edge R, Mc Garvey DJ, Truscott TG (1997) The caroteniods as antioxidants: a review. J Photochem Photobiol B: Biol 41:189-200
Ehling-Schulz M, Bilger W, Scherer S (1997) UV-B induced synthesis of photoprotective pigments and extracellular polysaccharides in the terrestrial cyanobacterium Nostoc commune. J Bacteriol 179:1940-1945

Fleischmann EM (1989) The measurement and penetration of ultraviolet radiation into tropical marine water. Limnol Oceanogr 34:1623-1629

Garcia-Pichel F (1994) A model for internal self-shading in planktonic organisms and its implications for the usefulness of ultraviolet sunscreens. Limnol Oceanogr 39:1704-1717

Garcia-Pichel F, Castenholz RW (1993) Occurrence of UV-absorbing, mycosporine-like compounds among cyanobacterial isolates and an estimate of their screening capacity. Appl Environ Microbiol 59:163-169

Garcia-Pichel F, Sherry ND, Castenholz RW (1992) Evidence for a $\mathrm{UV}$-sunscreen role of the extracellular pigment scytonemin in the terrestrial cyanobacterium Chlorogloeopsis sp. Photochem Photobiol 56:17-23

Garcia-Pichel F, Bebout PL, Muyzer G (1996) Phenotypic and phylogenetic analysis show Microcoleous chthonoplastes to be a cosmopolitan cyanobacterium. Appl Environ Microbiol 62:32843291

Häder D-P, Kumar HD, Smith RC, Worrest RC (2007) Effects of solar $\mathrm{UV}$ radiation on aquatic ecosystems and interactions with climatic change. Photochem Photobiol Sci 6:267-285

He Yu-Ying, Häder D-P (2002) UV-B-induced formation of reactive oxygen species and oxidative damage of the cyanobacterium Anabaena sp.: protective effects of ascorbic acid and $N$-acetyl-L-cysteine. J Photochem Photobiol B Biol 66:115-124

Helbling EW, Gao K, Ai H, Ma Z, Villafane VE (2006) Differential responses of Nostoc sphaeroides and Arthrospira platensis to solar ultraviolet radiation exposure. J Appl Phycol 18:57-66

Ivanov AG, Miskiewicz E, Clarke AK, Greenberg BM, Huner NPA (2000) Protection of photosystem II against UV-A and UV-B radiation in the cyanobacterium Plectonema boryanum: the role of growth temperature and growth irradiance. Photochem Photobiol 72:772-779

Karsten U (1996) Growth and organic osmolytes of geographically different isolates of Microcoleus chthonoplastes (cyanobacteria) from benthic microbial mats: response to salinity change. J Phycol 32:501-506

Karsten U (2002) Effects of salinity and ultraviolet radiation on the concentration of mycosporine-like amino acids in various isolates of the benthic cyanobacterium Microcoleus chthonoplastes. Phycol Res 50:129-134

Karsten U, Garcia-Pichel F (1996) Carotenoids and mycosporine-like amino acids compounds in members of the genus Microcoleus (cyanobacteria): a chemosystematic study. Appl Microbiol 19:285-294

Karsten U, Wiencke C, Kirst GO (1991) The effect of salinity changes upon the physiology of eulittoral green macroalgae from Antarctica and Southern Chile. J Exp Bot 42:1533-1539

Karsten U, Klimant I, Holst G (1996) A new in vivo fluorimetric technique to measure growth of adhering phototrophic microorganisms. Appl Environ Microbiol 62:237-243

Karsten U, Sawall T, Wiencke C (1998a) A survey of the distribution of UV-absorbing substances in tropical macroalgae. Phycol Res 46:271-279

Karsten U, Maier J, Garcia-Pichel F (1998b) Seasonality in UVabsorbing compounds of cyanobacterial mat communities from an intertidal mangrove flat. Aquat Microbiol Ecol 16:3744

Karsten U, Lembcke S, Schumann R (2007) The effects of ultraviolet radiation on photosynthetic performance, growth and sunscreen compounds in aeroterrestrial biofilm algae isolated from building facades. Planta 225:991-1000 
Kerfeld AC (2004) Water-soluble carotenoid proteins of cyanobacteria. Arch Biochem Biophys 430:2-9

Kruschell C, Castenholz RW (1998) The effect of solar UV and visible irradiance on the vertical movements of cyanobacteria in microbial mats of hypersaline waters. FEMS Microbiol Ecol 27:53-72

Nadeau TL, Williams CH, Catenholz RW (1999) Effects of solar UV and visible irradiance on photosynthesis and vertical migration of Oscillatoria sp. (cyanobacteria) in an Antarctic microbial mat. Aquat Microbiol Ecol 20:231-243

Neale PJ, Banaszak AT, Jarriel CR (1998) Ultraviolet sunscreens in Gymnodinium sanguineum (Dinophyceae): mycosporine-like amino acids protect against inhibition of photosynthesis. J Phycol 34:928-938

Paterson DM (1994) Microbial mediation of sediment structure and behaviour. In: Stal LJ, Caumette P (eds) Microbial mats-structure, development and environmental significance. NATO ASI Series, vol 35. Springer, Berlin, pp 97-110

Pattanaik B, Adhikary SP (2004) Effects of UV-B irradiation on survival, spectral characteristics and nitrogenase activity of cyanobacteria from different habitats. Algol Stud 113:159-173

Pattanaik B, Sahu JK, Adhikary SP (2004) Changes in the protein profile of cyanobacteria from terrestrial habitats in response to heat and UV-B radiation stress. Algol Stud 113:175-182

Pattanaik B, Schumann R, Karsten U (2007) Effects of ultraviolet radiation on cyanobacteria and their protective mechanisms. In: Seckbach J (ed) Cellular origin, life in extreme habitats and astrobiology: algae and cyanobacteria in extreme environments. (COLE) Book Series, vol 11. Springer, Netherlands, pp 29-45

Portwich A, Garcia-Pichel F (1999) Ultraviolet and osmotic stresses induce and regulate the synthesis of mycosporines in the cyanobacterium Chlorogloeopsis PCC 6912. Arch Microbiol 172:187192

Potts M (1994) Desiccation tolerance of prokaryotes. MicrobRev 58:755-805

Prufert-Bebout L, Garcia-Pichel F (1994) Field and cultivated Microcoleus chthonoplastes: the search for clues to its prevalence in marine microbial mats. In: Stal LJ, Caumette P (eds) Microbial matsstructure, development and environmental significance. NATO ASI Series, vol 35. Springer, Berlin, pp 111-116

Quesada A, Vincent WF (1997) Strategies of adaptation by Antarctic cyanobacteria to ultraviolet radiation. Eur J Phycol 32:335-342

Roleda MY, van de Poll WH, Hanelt D, Wiencke C (2004a) PAR and UVBR effects on photosynthesis, viability, growth and DNA in different life stages of two coexisting Gigartinales: implications for recruitment and zonation pattern. Mar Ecol Prog Ser 281:3750

Roleda MY, Hanelt D, Kräbs G, Wiencke C (2004b) Morphology, growth, photosynthesis and pigments in Laminaria ochroleuca (Laminariales, Phaeophyta) under ultraviolet radiation. Phycologia 43:603-613

Roleda MY, Clayton MN, Wiencke C (2006) Screening capacity of UV-absorbing compounds in spores of Arctic Laminariales. J Exp Mar Biol Ecol 338:123-133

Schoenwaelder MEA (2002) Physode distribution and the effect of 'thallus sunborn' in Hermosira banksii (Fucales, Pheaophyceae). Bot Mar 45:262-266

Shirkly B, Kovarcik D-P, Wright DJ, Wilmoth G, Prickett TF, Helm RF, Gregory EM, Potts M (2000) Active Fe-containing superoxide dismutase and abundant sodF mRNA in Nostoc commune (cyanobacteria) after years of desiccation. J Bacteriol 182:189197

Sinha RP, Ambasht NK, Sinha JP, Klisch M, Häder D-P (2003) UV-B induced synthesis of mycosporine-like amino acids in three strains of Nodularia (cyanobacteria). J Photochem Photobiol B Biol 71:51-58

Stal LJ (1995) Physiological ecology of cyanobacteria in microbial mats and other communities. New Phytol 131:1-32

Starr R, Zeikus J (1987) UTEX-the culture collection of algae at the University of Texas at Austin. J Phycol (Suppl) 23:1-47

Vincent WF, Quesada A (1994) Ultraviolet radiation effects on cyanobacteria: implications for Antarctic microbial ecosystem. In: Weiler CS, Penhale PA (eds) Ultraviolet radiation in Antarctica: measurements and biological effects Antarctic research series, vol 62. American Geophysical Union, Washington, pp 111-124

Wachi Y, Burgess JG, Iwamoto K, Yamada N, Nakamura N, Matsunaga T (1995) Effect of ultraviolet-A (UV-A) light on growth, photosynthetic activity and production of biopterin glucoside by the marine UV-A resistant cyanobacterium Oscillatoria sp. Biochem Biophysics Acta 1244:165-168

Wu H, Gao K, Villafane V, Watanabe T, Helbling EW (2005) Effects of solar UV radiation on morphology and photosynthesis of filamentous cyanobacterium Arthrospira platensis. Appl Environ Microbiol 71:5004-5013

Wulff A, Mohlin M, Sundbäck K (2007) Intraspecific variation in the response of the cyanobacterium Nodularia spumigena to moderate UV-B radiation. Harmful Algae 6:388-399 